\title{
CELESTINESCA
}

https://doi.org/10.7203/Celestinesca.12.19683

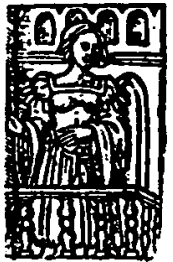

\section{PARALELISMOS EN LOS ENAMORAMIENTOS DE CALISTO Y TIRANT LO BLANC: \\ LOS PRIMEROS SINTOMAS DEL "MAL DEL AMAR".}

\author{
Rafael Beltrán \\ Universidad de Valencia
}

\section{Tirant lo Blanc y Celestina frente à frente.}

Hemos querido utilizar un celebrado calambur de Tirant lo Blanc-"jo no tinc altre mal sino de l'aire de la mar [l'aire del amar]"--, con el fin de anticipar, desde la primera linea, y aun antes, desde el mismo título de nuestro articulo, lo que en resumidas cuentas pretende ser su objetivo: dar a conocer un poco mejor a Tirant lo Blanc, notable héroe de libro de caballerias catalán, altivo antecedente de Amadis para unos, aburguesado incitador de Don Quijote para otros, en su faceta de héroe sentimental. $Y$ hacerlo intentando parangonar los primeros sintomas de su temible enfermedad amorosa con los que, pocos años después, algunas leguas más lejos, otro joven, de nombre Calisto, habrá de sufrir, con no menores desazones ni más fácilmente sofocables ardores, en la imaginación--gracias a la pluma--de un bachiller llamado Fernando de Rojas.

En los estudios más conocidos sobre la Celestina apenas ha sido mencionada más que como referencia esporádica la obra de Joanot Martorell y Marti Joan de. Galba, Tirant lo Blanc, considerada la mejor novela de la literatura catalana medieval y una de las mejores también-seguramente la de más talla en el siglo XV--de la literatura europea en el Medievo. ${ }^{1}$ Pero tampoco en la bibliografia tirantesca (o tirantiana), desafortunadamente muchisimo menos abundante, pasa de ser la Celestina el clásico extranjero de cita a veces obligada o formal. La excepción que confirma la regla seria la de un breve, denso y discutible artículo de Frank Pierce, "The role of sex in Tirant lo Blanc," que dejaria huella en futuras aproximaciones y donde se hablaba de la Tragiconedia como "perhaps the closest parallel in time and manner to the "Tirant". Tenia Pierce buen cuidado, sin embargo, de puntualizar las diferencias existentes entre ambas obras en el tratamiento del conflicto amoroso y en el uso de fórmulas para expresar el mismo. ${ }^{2}$ 
Refrescar unos datos previos, respecto a la novela catalana, puede ayudarnos a centrar el tema que abordamos. La fecha de escritura de Tirant lo Blanc continúa siendo dificil de precisar con exactitud. Martorell, en la enigmática dedicatoria de su novela, parece decir que la ha comenzado en 1460 . Pero el caballero valenciano muere en 1468, de jando inacabada, no sabemos exactamente en qué punto, la mayor parte de la extensa obra. Es relevado, tampoco conocemos en qué momento, por Marti Joan de Galba, quien modifica (pero, ¿en qué medida?) y da punto final al trabajo del primer autor, muriendo sólo unos meses antes de que la obra salga impresa. ${ }^{3}$

Tirant lo Blanc es acabado de imprimir, en su catalán original, el 20 de noviembre de 1490 . Ve la luz en Valencia, salido de las cajas de imprenta del alemán Nicolau Spindeler. Conocemos por el contrato de esta primera edición que constaba de 715 ejemplares, un verdadero éxito literario. En cálculos de Martí de Riquer, esta tirada equivaldría a unos 8.250 ejemplares en la actualidad, lo que, teniendo en cuenta el vertiginoso crecimiento de lectores desde entonces, aun en una lengua oprimida como la catalana, representa una alta cifra. Da fe de ese éxito el hecho de que la edición se debió agotar antes de siete años, puesto que en 1497 se volvía a imprimir la obra, esta vez en Barcelona. Esta nueva edición fue terminada, a causa de la muerte del primer editor, por el castellano Diego de Gumiel, un relevo en la carrera editorial que significará un factor nada casual en la futura divulgación del texto.

El éxito de la edición catalana no pudo repetirse. A partir de la unificación de las dos coronas, la penetración literaria del castellano en zonas catalano-hablantes avanzó imparable y la novela no pudo volver a reeditarse, en su texto original catalán, hasta finales del siglo pasado. ${ }^{4}$ Sin embargo, en el siglo XVI, el mismo responsable de la edición de Barcelona, Diego de Gumiel, trasladado a Valladolid, publicaria alli, en 1511, una traducción al castellano de la obra, dirigida a un nuevo público y anónima.

La traducción castellana de Tirant lo Blanc aparecía con extraordinaria oportunidad, durante la que Curto Herrero ha llamado etapa de formación del género del libro de caballerías castellano (15081511). En 1508 se habian publicado los cuatro libros de Amadis de Gaula, a los que seguirian dos años después las Sergas de Esplandián. Don Florisando (1510), Palmerín de Oliva (1511) y Primaleón (1512). La misma recuperación de El caballero Cifar, en 1512, puede dar idea de la aparentemente indiscriminada voracidad lectora de un público, al que le eran of recidas como contemporáneas suyas obras con hasta dos siglos (o más de veinte ańos, en el caso de Tirant lo Blanc) de antigüedad. ${ }^{b}$

Tal vez, como opinaba Menéndez Pelayo, la traducción castellana de la obra resultara excesivamente "esporádica," es decir, extraña, una 


\section{CELESTINESCA}

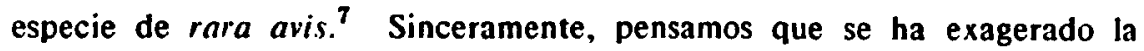
excepcionalidad (en el sentido etimológico, no en el ponderativo de la palabra) de Tirain lo Blanc, confundiendo a menudo su evidente originalidad con una ilógica e imposible extemporaneidad. Un estudio profundo de su influencia, a partir de la traducción de Valladolid, sobre algunos libros de caballerias castellanos del $X V I$, seguramente revelaría mayores indices de lectura y receptibilidad del texto que lo que se piensa. Pero lo cierto del caso es que, pese a esa razonable sospecha, tampoco durante el siglo XVI volvemos a encontrar reeditada en castellano la obra. Su fortuna literaria, sin embargo, no mengua, en todo caso se traslada. Viaja ahora a Italia, donde, a partir de la traducción que sobre el texto catalán realiza Lelio di Mandredi, será editada, con el título de Tirante il Bianco, en Venecia, 1538, reimpresa una segunda vez en 1566 , y una tercera en 1611 , siempre en Venecia.

Si quisiéramos hablar acerca de la posible influencia de Tirant to Blanc sobre los libros de caballerias castellanos del XVI, o sobre la descendencia celestinesca, podriamos remontarnos fácilmente, por tanto, a los años inmediatamente posteriores a la traducción castellana de Valladolid (1511). En cambio, si pretendiéramos fundamentar una hipótesis de influencia del texto de Martorell y Galba sobre el de Rojas, nuestro interés deberia quedar centrado en el lapso que va desde la edición catalana de Valencia, en 1490, hasta la de Barcelona, en 1497, o en los dos años, como mucho, posteriores a esta última. Es decir, tendríamos que acudir al tiempo en que la obra fue más divulgada y leida (en catalản, pero, ¿tal vez ya en una traducción castellana, la publicada en 1511?), como prueba, repetimos, la edición de 1497, a los únicos años en que pudo ser conocida por el autor de la primitiva Comedia o por el propio Rojas.

El rico manantial de fuentes de la Celestina no ha dejado, ni tiene por qué dejar de manar, por el hecho de que nos haya inundado con una bibliografia ya dificilmente abarcable en su totalidad, y no podemos negar a priori que Fernando de Rojas, o el autor del primitivo Auto I, pudieran haber conocido parcial o totalmente el texto de Martorell y Galba, que después iba a ser utilizado, directa $o$ indirectamente, nada menos que por Ariosto o por el mismo Cervantes. ${ }^{8}$ Nuestra intención va a ser la de permitirnos conceder algo más que el beneficio de la duda a esa hipotética influencia, tratando de ofrecer, a través de la revisión de algunos paralelismos entre algunas escenas de ambas obras, y en concreto las correspondientes al inicio del enamoramiento de los protagonistas, suficientes indicios para que futuros estudios puedan afrontar más exhaustivamente el tema. Nos conformariamos, pues, con tratar de sugerir que, dada su relevante, aunque aparentemente fugaz fama literaria, el texto catalán, y también el castellano de Tirant lo Blanc. pueden ser incorporados a la nómina de posibles influencias, el primero 


\section{CELESTINESCA}

sobre la misma Celestina, y ambos--aunque preferentemente el segundo-sobre la llamada descendencia de Celestina:

Al referirnos exclusivamente a los capitulos del enamoramiento del héroe en Tirant lo Blanc, vamos a evitar el tener que resumir toda la larga y compleja trama anterior de la novela, ciñéndonos desde el principio al encuentro del protagonista, Tirant, con la Princesa Carmesina, hija del Emperador del Imperio Griego, que ocupa en sus primeros pasos tan sólo cuatro capitulos del libro (caps. CXVII-CXX) ${ }^{9}$. Dicho encuentro tiene su paralelo argumental en el mismo inicio de la Celestina, por lo que nos servirá como perfecto punto de partida comparativo. ${ }^{10}$

2. El lugar del encuentro: "Veo ... la grandeza de Dios" / "Veig ... tantes coses admirables."

El encuentro de los principales protagonistas se da en situaciones y contextos muy diferentes en las dos obras. En una habitación del palacio del Emperador de Constantinopla, en Tirant lo Blanc, en el huerto de las casa de Melibea, en la Celestina. En principio podemos pensar que sólo una vaga relación los podria emparentar: la que procede de ocupar el lugar del encuentro, en ambos casos, un espacio artificiosamente literaturizado. Pero ese motivo, además del hecho de que exista un cierto paralelismo entre el desconcierto de Calisto y su nueva sensación de sentirse agraciado (su "cuerpo glorificado" por la visión de Melibea), y el toque de humor con que va a ser descrito el descubrimiento de Carmesina por parte de Tirant, no nos parecen suficientes indicios como para pensar más allá de que nos encontramos ante el tópico del encuentro entre jóvenes ardientes, futuros amantes.

Sin embargo, preferimos ir más allá de las apariencias y explorar con mayor detenimiento esos lugares de encuentro. Vayamos primero con el espacio de la escena que abre la Celestina. Calisto y Melibea ya parecen conocerse cuando se encuentran, puesto que se dirigen el uno al otro con sus propios nombres: "En esto veo, Mclibea, la grandeza de Dios". "¿En qué. Calisto?". Se trata, como se ha apuntado, de un comienzo in medias res. Los jóvenes se reconocen, no se presentan (Tirant, en cambio, descubrirá a Carmesina por primera vez a la vista del lector).

Contamos, de todos modos, con que una presumible falta de cohesión de parte del contenido del Auto I de la Celestina se pudo haber debido a las modificaciones que Rojas imprimiria en el Auto primitivo, aunque no podemos entrar nosotros ni siquiera a resumir un problema tan complejo como es el que afecta a la doble autoría de la obra. En cambio, si se nos va a permitir al menos traer a colación la, no por antigua, menos lúcida $y$ atendida sugerencia de Martin de Riquer respecto a que la primera escena del primer acto transcurriria en su forma primitiva, no en 


\section{CELESTINESCA}

el huerto de Melibea, como reza el "Argumento del primer auto," y como se ratifica en diversas alusiones internas al texto después, sino en un ámbito igualmente tradicional, pero mucho más lógico para las circunstancias de la entrevista e incluso más coherente para el correcto entendimiento de la primera conversación: una iglesia. ${ }^{11}$

En una iglesia, dice Riquer, cobraria todo su sentido el equivoco de Calisto respecto al referente de "En esto veo (...) la grandeza de Dios". El deictico, en boca de Calisto y refiriéndose al espacio que los rodeaba, sería redundante y obvio, y motivaria--una manera como otra cualquiera, more ovidiana, de captar la atención de la doncella, para trabar conversación--la ingenua contestación de Melibea: " ¿En qué. Calisto?" (en qué, concretamente, pues en una iglesia se supone que se encuentra la grandeza de Dios por doquier). Alli cobrarian tambièn su sentido las referencias a "el servicio. sacrificio. devoción $y$ obras pias que por este lugar alcanzar yo lengo a Dios ofrecido," es decir las promesas y of recimientos hechos a Dios por Calisto para obtener la oportunidad de hablar a Melibea "en tan conveniente lugar," en una iglesia.

Pero entendámonos. No pretendemos entrar a defender de buenas a primeras, y menos con argumentos tan conocidos, la posibilidad de que el encuentro primero, en un texto primitivo, se celebrase en una iglesia. $Y$ eso que en una iglesia, nada menos que en la magnífica Santa Sofia de Constantinopla, irá a encontrar Tirant a su amada, aunque en su segundo dia de encuentro, como hemos de ver más adelante. Pero no queremos hacer paralelismos gratuitos ni fortuitos, entre otras cosas, porque, aunque la curiosidad nunca se conforma con lo que le es dado a primera vista, el texto de la Tragicomedia nos hablará indudablemente--aunque no en esta escena--de un "huerto" ( $o$ "huerta") y para nada va a mencionar una iglesia. Lo que pretendemos, de momento, al traer a colación la hipótesis de Riquer que, por otra parte y teniendo en cuenta las aclaraciones anteriores, nos sigue pareciendo perfectamente plausible, es confirmar que la ambigüedad y la polisemia del texto se mantienen, aunque cambie el "lugar," en las maliciosas referencias de Calisto, a renglón seguido, al "lugar conveniente" que pretende "alcanzar," a "este lugar," que precisamente por la obviedad del deíctico tenia que significar "este [otro] lugar," el lugar secreto o prohibido del sexo, como Paul Lecertua-relacionando "lugar" con "huerto" o "huerta," pero nunca con iglesia--ha analizado perspicazmente. ${ }^{12}$

En definitiva, el descubrimiento y admiración primeras son del cuerpo y sobre el cuerpo femenino en ambos casos, y a partir de esa admiración se cebará la ironía de los autores. Porque la reacción de los amantes, se nos va a sugerị,, es irracional. En ambos casos los protagonistas masculinos se comportarán estúpidamente. Sus primeras reacciones o palabras serán desproporcionadas respecto al hecho mismo de 


\section{CELESTINESCA}

la aparición de la doncella. Asi, Rojas quiere mostrar esa exageración en las palabras de Calisto, que inician su discurso:

- ¿En qué, Calisto?

- En dar poder a natura que de tan perfecta hermosura te dotase y hacer a mi inmérito tanta merced que verte alcanzase y en tan conveniente lugar que mi secreto dolor manifestarte pudiese."

El hipérbaton, el homoteleuton ("dotase," "alcanzase," "pudiese") y la aposición del cultismo "inmérito," hacen que la segunda frase de Calisto en la obra resuene con una pomposidad extrema. El autor coloca a Calisto desde el principio como enunciante de un discurso repleto de despropósitos y sobreactuaciones. Por eso aconsejará Proaza a quien le corresponda leer a Calisto: "Si amas y quieres a mucha alención / Levendo a Calisto mover los oyentes, / Cumple que sepas hablar (...) / A veces con gozo, esperanza y pasion. / A veces airado, con gran turbación"). Porque su comportamiento es, como poco, desconcertante (" $a$ veces... a veces..."). Por eso, el diálogo deriva hacia el ridiculo (la "pasión" es risible), cuando Calisto, al escuchar la palabra "galardón" en boca de Melibea--y entenderlo no precisamente en su sentido más recto--replica con ese: ";Oh bienaventuradas orejas mias, que indignamente tan gran palabra habeíis oido!" $O$ basta atender de nuevo a sus improcedentes cultismos, tras la reprimenda que la aparentemente fácil Melibea le endilga en reproche a su atrevimiento:

"Iré como aquél contra quien solamente la adversa fortuna pone su estudio con odio cruel."

Vamos a encontrar en la contemplación, por parte de Tirant, del cuerpo de Carmesina, una muy semejante extremosidad, y dentro también de un ámbito artificioso y literaturizado como el de la Celestina. No se trata de un huerto, ni--por ahora, en este primer dia--de una iglesia. Nos encontramos en una habitación del palacio del Emperador en Constantinopla. A Tirant le ha sido concedido, en virtud de su cargo de Capitán, llegar a acercarse a los pies mismos del lecho de la Princesa. El Emperador le conduce, antes que a la cámara de su hija, a la de su esposa, donde "la cambra era moll escura sens que no hi havia llum ni claredal neguna." La razón de esta oscuridad estaba en el luto impuesto en la corte a causa de la reciente muerte del hijo del Emperador. Afortunadamente, y después de un gracioso reproche de Tirant respecto a que, habida cuenta la oscuridad, tenia que creer "per $f e^{n}$ que de verdad estaba hablando con quien le presentaban, el Emperador le da potestad para suspender - el luto $y$ traer antorchas que iluminen las oscuras habitaciones. Asi to hace Tirant. Y de ese modo descubre primeramente a la Emperatriz, y a continuación a la Infanta su hija, reposando ésta en un lecho circundado nada menos que por ciento sesenta damas y doncellas. 


\section{CELESTINESCA}

Más explicita en cuanto a la corporeidad, y también más graciosa en lo que respecta a la comparación, la hipérbole de admiración ante la dama, en el caso de Tirant lo Blanc, no está en boca del protagonista, sino del narrador:

"E per la gran calor que feia (...) estava mig descordada mostrant en los pils dues pomes de paradis que crestallines parien. les quals donaren entrada als ulls de Tirant. que d'alli avant no trobaren la porta per on eixir..."

Como Calisto, que "gozaba" más que los santos en el "acalamiento" del cuerpo de Melibea, también Tirant goza a su antojo en el "acatamiento" del cuerpo de Carmesina. El equivoco sacroprofano en Celestina parece aqui más inocente y se disuelve en metáfora y juego de palabras: la de la (puerta de) "entrada" y la "puerla de salida." .Aunque, si hemos de seguir las valiosas interpretaciones de Lecertua, la utilización de "puerta" en Celestina posee también fuertes connotaciones sexuales. ${ }^{13}$ El equivoco, por otro lado, habia sido inducido algo antes, cuando la voz del narrador acotaba las palabras del Emperador, señalando picaramente lo que Vargas Llosa, refiriéndose a esta misma cita, ha caracterizado como una duplicidad, una falla, por la que el lector pudo irrumpir en el mundo interior de Tirant y descubrir su vida afectiva:

"dient l'Emperador tals o semblants paraules les orelles de Tirant estaven atentes a les raons. e los ulls d'altra part contemplaven la sran bellea de Carmesina." 14

Todo, incluso la utilización humorística del paralelismo, que podriamos confrontar con el vulgarizador $e$ irónico empleo de las "bienaventuradas orejas" por parte de Calisto, remite, en este primer encuentro, como en el equivoco primer diálogo entre Calisto y Melibea, al alegre goce de los sentidos, al gozo del "acalamiento" o la "contemplación"...

Martorell ha insistido en la conmoción que produce la aparición: "Mas sé-us bé dir, certament. que los ulls de Tirant no havient jamés rebut semblant past, per moltes honors e consolacions que s'hagués vistes. com fon sol aquest de veure la Infanta." La utilización de "pasto" como alimento, comida para los ojós, parece una metáfora compleja y un tanto extravagante. Resulta algo inconsecuente, no ya la reducción despectiva del cuerpo femenino a alimento, que utiliza también Calisto al hablar, en vez de "pasio," de "pan," sino la cosificación del cuerpo, recièn descrito como paradisiaco, en un contexto tan supuestamente idealizador. Sólo podemos interpretar que el autor ha decidido romper con la sublimada intensidad de este momento clave del acceso amoroso, introduciendo un término bajo, vulgarịador $y$, por contraste, risible, que obliga a ironizar sobre el mismo tópico amoroso dél que se está sirviendo. ${ }^{15}$ 


\section{CelestinesCa}

El equivoco continuará, una vez salidos de la habitación de la Princesa, cuando ingresen en otra vecina, toda ella pintada o tapizada con motivos de los amores de Flores y Blancaflor, Piramo y Tisbe, Dido y Eneas, Tristán e Isolda, Lanzarote y Ginebra, y otros míticos amores. Detengámonos en esta magnifica sala bizantina. Recordemos ahora el lugar / huerto / huerta, pensemos en la supuesta iglesia del primer encuentro en Celestina... Y leamos, recordando la irónica ambigüedad de los deicticos en el habla de Calisto, el comentario de Tirant a su amigo Ricard:

"-No creguera jamés que en aquesta terra hagués tantes coses admirables com veig".

Observemos más despacio la correspondencia:

TIRANT "Veig ... tantes coses admirables" (espacio secular)

CELESTINA "Veo .... la grandeza de Dios" (espacio religioso o locus amocnus)

Martorell explicará, por si no ha captado el lector el equivoco, la ambigüedad de las palabras de Tirant:

"E dcia-ho més per la gran bellea de la Infanta. Emperò aquell [Ricard] no ho entès."

Es como si, a las primeras palabras de Calisto: "En esto veo. Melibea. la grandeza de Dios," Rojas hubiera apostillado: entendio."

"Y lo decía por la gran belleza de Melihea. Pero ella no lo

De hecho, Melibea no le ha entendido. su lacónico: "En qué...?" da pie a que el enamorado continúe su retahila de equívocas alusiones, hasta que, entonces si, al descubrir Melibea la ingenuidad de su primera-y lógica--asociación, entendido el engaño del embaucador, reaccione incluso violentamente, en un brusco cambio de actitud, que no ha solido ser bien comprendido.

El equivoco del espacio aludido con el que se juega en ambas obras es idéntico:.

"Veo la grandeza / lo admirable de..."

[ESPACIO LITERARIO SUPUESTO POR EL CONTEXTO = Demostrativo ("esto") / Indefinido ("tantas cosas") ]

"Veo la grandeza / lo admirable de..."

[REALIDAD PRESENTE ELIDIDA = el cuerpo femenino de Carmesina / Melibea ]. 


\section{CELESTINESCA}

Pero es necesario que se trate de un espacio extraordinario, de un espacio (secular o laico) ponderable, que dé pie al juego de la ironia. Por esa razón, y porque el "locus amocnus" del vergel, por paradisiaco que sea, no se prestaba a ese tipo de ponderaciones, tenemos que asumir las sospechas de Riquer y yendo un poco más allá; pensar que los equivocos entre los lugares eróticos y los lugares religiosos en la Comedia pudieron resultar excesivamente procaces incluso a un atrevido como. Fernando de Rojas, quien podria haber sustituido un lopos literario por otro mucho menos temerario y que le permitiera también a su obra una mayor economia escénica con menor dispersión de espacios.

\section{El abatimiento.}

"...holgando con lo escuro,deseando soledad..."

Las subsiguientes reacciones del amante, tras el inesperado encuentro, van a ser descritas en ambos casos en un nuevo contexto espacial, esta vez si común: la intimidad de sus respectivas habitaciones, en la casa de Calisto y en la posada donde se hospeda Tirant. La habitación, lo sabemos, es durante el Medioevo lugar donde los sentimientos más profundos (el temor, la ira, el amor) pueden ser desahogados sin temor a la vergüenza de la luz pública. Además, en ambos casos tambièn encontraremos a un interlocutor del protagonista, que servirá para explicitar el proceso de enamoramiento de éste, y para contrapuntear, con su normalidad y sensatez, la locura o estupidez del ofuscado amante. Como acusará Sempronio: "Que en viéndote solo. dices desvarios de hombre sin seso, sospirando, gimiendo, maltrovando. holgando con lo escuro. deseando soledad..." (Auto II)

El primer sintoma de la locura de amor es el del abatimiento, y por ello ambos héroes buscan el amparo del lecho para reposar el cuerpo y enjugar sus lágrimas. En el texto catalán: "Tirant pres llicéncia de tots $e$ anà-sén a la posada. entrà-se'n en una cambra e posà lo cap sobre un coixi als peus del llit." Le basta a Martorell el uso de estas tres yuxtaposiciones y, sobre todo, la inclusión del detalle delicioso del cambio de la almohada a los pies de la cama, para sugerirnos sutil y tiernamente el estado de postración de Tirant.

También Calisto busca el descanso del lecho para recrearse consigo mismo en sus sufrimientos: "iAnda. anda. malvado. ahre la cimara y" endereza la cama!," le dira a Sempronio, que no ha cometido otra maldad que la de haber estado ocupándose de los caballos y de la alcándara del gerifalte. Y. luego: "Cierra la ventana y deja la tiniebla acompañar al triste y al desdichado la ceguedad. Mis pensamicmos tristes no son dignos de luz." 
Hay un curioso paralelo tambièn entre estas referencias, en boca de Calisto, a la tiniebla como símbolo y sintoma de tristeza y desdicha, y el capitulo de Tirant lo Blainc, al que ya nos hemos referido, inmediatamente anterior al de la escena de la visión de Carmesina. Todo ese capitulo previo se desarrollaba como un juego en el espacio real y en el simbólico entre la luz y la oscuridad. Asi, la llegada de Tirant al palacio tenia un doble sentido liberador: Tirant venía a romper con las tinieblas y/o con la reclusión. Sentido bien explicitado por Martorell: "E aparegué a toles les dames que fossen eixides de gran captivitat, per ço com havia molts dies que eren posades en tenebres per la mort del fill de l'Emperador."

En el mismo diálogo de Calisto con Sempronio (en realidad es casi un monólogo, pero Calisto no queda todavia solo) no deja tampoco de ser curiosa la referencia de Calisto a dos personajes, Piramo y Tisbe, que hemos encontrado en Tirant lo Blanc, recordemos, entre las pinturas miticas de la habitación en el palacio de Constantinopla: " $\mathrm{Oh}$ piedad de Seleuco, inspira en el plehérico corazón por que sin esperanza de salud no envie el espiritu perdido con el desastrado Piramo y de la desdichada Tisbe!" En ambos casos, las referencias cultas a personajes históricos o literarios, es decir las parejas de grandes amadores, en Tirant, y las apelaciones a "Eras" y "Crato" (o Erasistrato), a "Seleuco," al "plebérico corazón," y a Piramo y Tisbe, en Celestina, envuelven al protagonista en un halo mitico-literario (como supo captar perfectamente Vargas Llosa para el caso de Tirant) muy propicio para sugerir el estado al que le está conduciendo sin remedio su irrefrenable pasión: el abandono de la realidad objetiva y el ingreso en la imitación de los ideales y perjudiciales munidos amorosos de la ficción, y en concreto de la ficción sentịmental o del amor cortés. ${ }^{16}$

\section{La presencia del interlocutor.}

La presentación y presencia del interlocutor en .esta segunda "escena" tienen unas caracteristicas y desarrollo distinto en las dos obras, puesto. que de muy, distinta clase son también los personajes. Fundamentalmente son de muy distinta clase social. En Tirant lo Blanc, el interlocutor va a ser su primo y amigo Diafebus, un caballero como él, un igual. En el de Calisto, su criado Sempronio, hombre inteligente, pero servidor al fin, y no precisamente dócil, como hará ver más adelante. Aunque Sempronio pronto va a demostrar una nada desdeñable cultura, sabe hacer hipócritamente su papel de criado inculto cuando le conviene. $Y$ asi contesta a los desvarios en jérga cultista de su abatido amo con un "¿Qué cosa es?," que puede valer por un despectivo: "Pero, ¿qué dices? ¿No entiendo nada!"

Ambos interlocutores se preocupan, ya con sinceridad, ya por curiosidad, por los enfermos de amor. Ante las solicitas preguntas de Diafebus, 
Tirant pretende simular la causa verdadera de su enfermedad utilizando el magnifico calambur con el que iniciábamos el articulo: "jo no tinc altre mal sinó de l'aire de la mar [l'amar] qui m'ha tot comprès." Cuando Diafebus insiste en que le haga participe de sus cuitas, Martorell hace que Tirant demuestre, por vez primera en propia boca, como ya hemos visto que lo habia hecho Calisto, to exagerado de sus exaltados sentimientos y lo ridiculo del discurso en que se expresan èstos:

"No vullau més turmentar la mia persona--dix Tirant--. que jamés sentí tan greu mal com lo que ara sent, que em farà venir prest a mort miserable o a gloria reposada si fortuna no miés contrària. car la fi de totes aquestes coses és dolor per aquella amor que és amarga."

Son términos hiperbólicos, aun dentro de la valenciana prosa del $\mathrm{XV}$, y términos exaltados, incluso dentro de ese contexto, comparables (basta observar a nivel fónico las forzadas aliteraciones en ambos casos) a los que Calisto profiere ante Sempronio: "iVete de ahi! No me hables; si no quizá ante del tiempo de mi rabiosa muerte. mis manos causarán tu arrebatado fin."

\section{La confesión del amor.}

Prueba de la diferencia social de los interlocutores en la Celestina es, además del diferente tono empleado, el hecho de que, mientras que Tirant acaba confesánđose al amigo Diafebus con un lacónico: "Jo ame," Calisto, en cambio, manda al diablo, literalmente, a Sempronio. En ambos casos, sin embargo, se desvela el secreto que reconcomia a los amantes, se descubre que se trata del mal del amar, y no el mal de la mar, como decia equivocamente Tirant. O como contestará con toda lógica Sempronio a la pregunta de Calisto: "¿Qué te parece de mi mal?," que el problema es sencillamente: "Que amas a Melibea" (cfr. de nuevo la sencillez del "Jo ame" de Tirant).

\section{Melancolia}

Una vez aliviada la confesión, en el caso de Tirant, o expulsado Sempronio de la habitación, en el de la Celestina, los amantes se hunden por igual en la melancólica debilidad de las lágrimas. Tirant, "acabant-ho de dir, dels seus ulls destil.laren vives llàgremes mesclad's ab sanglots e sospirs." Y: "Dejemos llurar al que dolor tiene"--dice Sempronio, expectante y dubitativo, esperando a la puerta la llamada del amo--, "que las lagrimas y sospiros mucho desenconan el corazon dolorido." Se produce entonces una especie de breve interludio, que precede al intento de consolación por parte de los interlocutores, y durante el cual éstos, en ambos casos, reflexionan o monologan. Diafebus to hace (piensa en voz alta, y de hecho hay un fallo narrativo, porque el autor pasa de la tercera 


\section{CELESTINESCA}

a la primera persona sin aviso), pensando en lo remiso que se habia mostrado hasta entonces Tirant en asuntos de amor. Sempronio tambièn reflexiona, alta voce, dudando entre qué actitud tomar, si la de la ayuda o la del abandono, si la del interés o la del desentendimiento.

\section{Consuelo}

Después de ese lacrimógeno interludio, ambos interlocutores procuran consolar a los enfermos. Lo hacen, eso sí, de muy distinta manera, de acuerdo con sus diversas condiciones sociales. Nada tiene que ver la serena y comprensiva actitud de Diafebus hacia su amo, con la de Sempronio, convertido en cantante de romances vulgares (en vez de las canciones de amor triste que se le piden) y que responde con una mezcla de sorna y sensatez, a las locas preguntas de un Calisto ya en franco desvario. Pero hay algo común, de nuevo, entre ambos. Se trata, claro está, de la promesa de solución que proponen, implicándose como cómplices de la pasión secreta. "Vós d'una part e jo d'altra, porem donar remei a la vostra novella dolor," comunica el resuelto Diafebus al inmovilizado Tirant. Y Sempronio: "bien sé de qué pie coxqueas; yo te sanarc." $\quad \mathrm{Y}$ asi anunciarán el comienzo de un nuevo capítulo de las relaciones, el de la mediación de las segundas parejas en el argumento principal.

Del diảlogo con estos dos cómplices, los pobres enamorados van a salir confortados, siquiera temporalmente: "Com Tirant véu lo bon conhort que Diafebus li dava, restà molt aconsolat." En el caso de Sempronio, éste consigue hacer incluso reir a Calisto con sus chistes, especialmente con el magnifico sobre la sodomía.

\section{La superioridad de la dama}

Pese al consuelo of recido por los interlocutores, en ambos casos ha quedado como elemento de suspense la seria duda de los amantes sobre si estarán lo suficientemente dotados como para aspirar a las alturas en las que se instalan sus amadas. Tirant, "coneixent ab vivá raó que era pujat en més alt grau que ne devia." . Calisto, reconociendo que "amo a aquella ante quien tan indigno me hallo que no la espero alcanzar:" Se deduce, de aquí y de otros indicios, y a pesar del tópico cortés de la superioridad de la dama, una plausible diferencia social entre.Calisto y Melibea, que ha sido bien estudiada. : $Y$ comienza, en el caso de Tirant, una de las caracteristicas principales que guian su actuación futura y condicionan el desarrollo argumental de la novela: el interés por compensar con los hechos de armas su patente desventaja frente a la Princesa.

Sempronio parece cambiar de personalidad, desde el momento en que empieza a ilustrar a su amo con la lección misoginista que comienza: 


\section{CELESTINESCA}

"Escociote? Lee los historiales, estudia los filosofos...," y que termina con el miserable: "oh. qué hastio es conferir con ellas mas de aquel brcve tiempo que aparejadas son a deleite!" . Todo su imprecación va encaminada a elevar el ánimo de Calisto, acomplejado ante la mayor honra y linaje de Melibea, y a persuadirlo de su capacidad de conseguirla: "piensa ser más digno de lo que te reputas. Que cierto. peor extremo es dejarse hombre caer de su merecimiento. que ponerse en mas alto lugar que debe."

Sempronio es consciente de ser pieza clave en el proceso de persuasión. Tiene tal vez ya en mente a Celestina y ha barruntado los beneficios que le puede reportar su papel de mediador con ella. El siguiente paso es el de la adulación, con el fin de infundir la seguridad minima al enamorado: "Lo primero eres hombre y de claro ingenio; $y$ más. a quien la natura dotó de los mejores bienes que tuvo. conviene a saber: hermosura, gracia. grandeza de miembros, fuerza. ligereza..." Diafebus cumple, por su parte, con ese mismo papel adulatorio, pero sustituyendo a Tirant en la corte y relatando pormenorizadamente sus pasadas hazañas a los cortesanos. La adulación, en este caso, no se dirige a Tirant, aunque si revierte en beneficio suyo.

Pero el amor produce inseguridad en el más valiente. Calisto, en sus trece, insiste en demostrar a Sempronio la superioridad de Melibea, superioridad que, siguiendo la paradoja cortés, le hace sufrir al tiempo que adula su amor propio y le contenta: la nobleza y antigüedad de su linaje, el grandisimo patrimonio, el excelentisimo ingenio. las replandecientes virtudes. la inefable gracia. la soberana hermosura. de la cual te ruego mie dejes hablar un poco..."

De semejante complejo padece Tirant, quien pregunta desesperado a Diafebus: "¿Ab quin ànimo ni ab qual llengua parlar poré. que la puga induir e moure a pietat. con sa altesa miavança en totes coses. co és. en riquea, noblea e en senyoria?" (cap. . CXX). Nobleza, patrimonio o riqueza, y soberanía o señoría, los mismos valores que pondera Calisto en Melibea, ensalza Tirant en Carmesina. En ellos ven los dos, a la vez que deleite, impedimento para sus deseos últimos.

\section{La descriptio puellae (Melibea y Carmesina)}

Arle regendus Amor (Ovidio, Ars Amandi)

Para acabar casi con los paralelismos más importantes en estas primeras escenas, nos referiremos a uno que debe llamar poderosamente la atención. Se trata de la utilización en ambos textos del esquema de la "de'scriptio puellac," la descripción retórica de la doncella, siguiendo los preceptos de las artes poéticas y la nutrida tradición de numerosos textos de las leyendas de Troya y de la ficción sentimental: ${ }^{17}$ El uso de la 


\section{CELESTINESCA}

"descriptio puellae" no es insólito, todo lo contrario, en ninguna de las dos tradiciones literarias, castellana y catalana, y por tanto no debiera extrañarnos su empleo reiterado. No deja de ser algo más que curioso, sin embargo, que dicha descripción vaya insertada en las dos obras en un mismo contexto, el del enamoramiento del protagonista.

Veamos primero su inclusión en la menos conocida secuencia de Tirant lo Blanc, que ha solido pasar desapercibida. Con la descripción de la amada concluye el largo capitulo CXIX, que habia comenzado con el intento por parte de Diafebus de consolar a Tirant. Pese a haber quedado aliviado en su sufrimiento, Tirant no logra probar bocado ese dia. Tiene que salir del comedor precipitadamente, y encerrarse en otra habitación para esconder, avergonzado, su pasión. Diafebus, en tanto, va a comenzar una paciente labor de mediación, que ocupará muchos capítulos todavia en la obra, y que le relacionará a él mismo con Estefanía, prima y doncella de la Princesa Carmesina.

La descripción de Carmesina es insertada por Martorell, en una delicada escena de reminiscencias boccaccianas, como reflexión que Tirant realiza mientras la está contemplando a su antojo, ambos escuchando el oficio en la iglesia de Santa Sofia: "Com Tirant hagué molt bé contemplada la bellea singular de la Infanta, e lo seu enteniment discorregué fantasiant quantes dones e donzelles ell en son record haver vistes, e dix que jantés havia vista ni esperava de veure una altra tal qui fos dotada de tants béns de natura com aquesta. car aquesta resplandia en llinatge. en bellea. en gràcia, en riquea, acompanyada d'infinit saber, que més se mostrava angellica que humana (...) car eslava admirant dels seus cahells...".

Precisamente "angélica" será un cultismo que Rojas utilizará profusamente para ponderar los valores de Melibea: "angélica imagen", la llama Calisto en el Auto XIV (aunque también "gesto angélico y matador," en el Auto.VI); y algo más adelante, en su soliloquio: "Trae a mi fantasía [cfr. también el "fantasiant" de Tirant] la presencia angéllca de aquella imagen luciente," donde de nuevo el término se tornaria polisémico si remitiera a alguna de las imágenes iluminadas ("luciente" ) de un altar en la iglesia.

La descriptio en la Celestina forma parte del diálogo que mantienen Calisto y Sempronio. Por eso algunos de sus elementos serán parodiados por el interlocutor, Sempronio, quien aparentemente ajeno a esa tradición literaria (pese a sus recientes citas de Salomón, Séneca, etc.), contrapuntea la descripción de Calisto con irritantes acotaciones burlescas: 


\section{CELESTINESCA}

\section{TIRANT LO BLANC}

... admirant del seus

cabells, qui de rossor resplandien com si fossen madeixes d'or,

los quals per eguals parts departien una clenxa de blancor de neu passant per mig del cap;

e estava admirant encara de les celles, que paria fossen fetes de pinzell llevades, un poc en alt, no tenint negror d'espesura de pèls, mas estant ab tota perfecció de natura. més estava admirat dels ulls, que parien dues esteles redones relluints com a pedres precioses (...)

lo seu nas era prim e afilat e no.massa gran ni poc segons la llindesa de la cara, que era d'extrema blancor de roses ab lliris mesclada; los Ilavis tenia vermells com a coral e les dents molt blanques menudes e espesses que parien de crestall

\section{CELESTINA}

Comienzo por los cabellos. ¿Ves tú las madejas del oro delgado, que hilan en Arabia? Más lindos son y no resplandecen menos; su longura hasta el postrero asiento de sus pies; después crinados y atados con la delgada cuerda, como ella se los pone, no ha más menester para convertir los hombres en piedras.

[Aqui, una de las intervenciones impertinentes de Sempronio].

Ios ojos verdes, rasgados;

las pestañas luengas

Ias cejas,

delgadas y alzadas

la nariz

medlana

la boca pequeña;

los dientes menudos y blancos:

los labrios colorados y grosezuelos; 
[Cfr. en cap. CXVIII: "mostrant en los pits dues pomes de paradis que crestallines parien"]

E estava més admirat de les mans,

que eren d'extrema blancor e carnudes que no s'hi mostrava os negú, ab los dits llargs e afilats, les ungles canonades e encarnades que mostraven

portar alquena, no tenint en res negún defalt de natura el torno del rostro poco más luengo que redondo; el pecho alto; la redondeza y forma de las pequeñas tetas, ¿quién te la podria figurar? Que se despereza el hombre cuando las mira.

La tez lisa, lustrosa;

el cuero suyo escurece la nieve; la color mezclada, cual ella la escogió para sí. las manos pequeñas en mediana manera de dulce carne acompañadas

los dedos luengos las uñas en ellos largas $y$ coloradas, que parecen rụbies entre perlas.

Aquella proporción que ver yo no pude, no sin duda por el bulto de fuera juzgo incomarablemente ser mejor que la que Paris juzgó entre las tres Deesas." 


\section{CELESTINESCA}

\section{La promesa de colaboración del interlocutor}

La descripción de Melibea acaba en la Celestina con la apelación de Sempronio a Calisto para que regrese a la realidad, al buen sentido, y con la concesión del permiso, por parte de éste, para que el criado tome parte en la empresa de la mediania: "Y porque no te desesperes. yo quiero tomar esta empresa de cumplir tu deseo." Es la misma promesa, con las salvedades de ser ayudantes de muy distinta clase, que Diafebus dirige a Tirant: "vós d'una part e jo d'altra porem donar remei a la vostra novella dolor." Así se iniciará otro capítulo en las tramas de ambas narraciones, merecedor de una atención más detallada que la que por el momento podemos conceder.

\section{Aristóteles, como coda}

Pero quisièramos terminar con un ültimo (no el illimo) sorprendente paralelo. Se trata de una casi idéntica alusión al "filósofo," es decir a Aristóteles, por parte de ambos interlocutores $\mathrm{y}$, de nuevo, en el seno del mismo diálogo de convencimiento que mantienen con los enfermos de amor. Sempronio apostillaba la descriptio puellae de Melibea, sobre la que Calisto se acaba de extender a su gusto, del siguiente modo:

SEMP.- Puesto que sea todo eso verdad, por ser tii hombre eres más digno.

CAL.- ¿En qué?

SEMP.- En que ella es imperfecta. por el cual defecto desea y apetece a li y a otro menos que tii. ¿No has leido el filosofo, do dice: "Así como la materia apetece la forma, así la mujer al varón?"

Muy parecida es la respuesta que Diafebus da a Tirant, tras la primera confesión por parte de éste de su amor hacia Carmesina:

"-Natural condició és a la natura humana amar, car diu Aristòtil que cascuna cosa apeteix son semblant."

"Cascuna cosa apeteix son semblant" ha pasado a "la materia apetece la forma." Amar, desear, apetecer... Aun no siendo literalmente iguales, se trata de variaciones tópicas sobre una misma cita del "Filisofo."19

Pero tópica era también la descripción de la doncella. tópica la reclusión en la oscuridad benéfica del cuarto, y la confesión del amor, y el idéntico estado de lacrimógena melancolia, y el consuelo y promesas de ayuda por parte del interlocutor, y antes, al inicio, la utilización del equivoco humoristico sobre el lugar de encuentro de los amantes... Muchos tópicos parangonables entre ambas obras--1antos como 


\section{CELESTINESCA}

dificilmente encontrariamos entre dos obras de la época, y menos cuando un texto de la originalidad de la Celestina fuera uno de los términos de la comparación--y sorprendentemente aglutinados en una relativamente breve secuencia clave de la acción.

De la comparación de algunos de esos tópicos, - que hemos intentado ir desgranando a lo largo de este articulo, pensamos que se puede recoger la lección de que la proximidad entre ambos textos, tanto en elementos de retórica como de estructura y comportamiento de los personajes es indiscutible. Tengamos en cuenta que la escena acotada en este articulo, los primeros pasos del enamoramiento, no ocupa más de quince páginas en el caso de Tirant lo Blanc (mucho menos, claro está, en la Celestina), dentro de un texto de más de mil páginas. El estudio de otras escenas posteriores, que nos proponemos acometer, o en parte hemos analizado ya, confirma las convergencias. Esa constatación debe repercutir en primer lugar sobre el texto catalán, sobre la franca consideración de "comedia" de algunas de sus partes. Pero puede repercutir a más largo plazo, explorando más a fondo el origen y razones de ese por el momento todavia lejano parentesco, en el estudio de las influencias sobre Celestina de las obras--no sólo castellanas--salidas a la luz en las últimas décadas del siglo $\mathrm{XV}$.

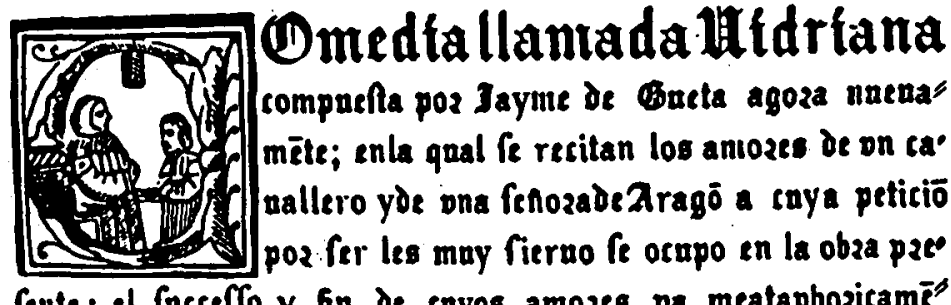
fente: el fuccefto y an de cuyos amozes oa meataphozitamés te tocado jufte elpzoceffo y execucion de aquellos.hay los in terlocutoses figuyentes. $\because$

Jaime de Huete. Comedia Vidriana. BN-Madrid. 


\section{CELESTINESCA}

\section{NOTAS}

'Como ejemplo significativo de esa escasez de referencias, citaremos el de $\mathbf{M}^{\mathrm{a}}$ Rosa Lida de Malkiel, La originalidad artistica de "La Celestina", Buenos Aires: Eudeba, 1970, donde encontramos tan sölo tres alusiones, ninguna verdaderamente significante, a Tirant lo Blanc (págs. 493,498 y 648, n.).

2 Estudis Romànics 10 (1962): 291-300, esp. pág. 299.

${ }^{3}$ Para estos datos, y otros muchos, remitimos a la edición, con amplia Introducción, de la obra, por parte de Marti de Riquer, Tirant lo Blanc, Barcelona: Ariel, 1979, que seguiremos en todo nuestro articulo. Para una bibliografía más actualizada sobre la obra, vid. la recopilada por Kathleen McNerney, "Tirant lo Blanc" Revisited. A Critical Study, Medieval and Renaissance Monograph Series, Detroit, 1983, y la mía propia, "Tirant lo Blanc": evolució i revolta de la narració de cavalleries, València: Institució Alfons el Magnànim, 1983. Entre los artículos más destacados, no recogidos en ellas, por aparecer posteriormente, destacaremos los de Arthur Terry, "Character and Role in Tirant lo Blanc," en Essays on Narrative Fiction in the Iberian Peninsula in Honour of Frank Pierce, ed. R. B. Tate, Oxford: Dolphin, 1982, págs. 177-95 (traducido como "El paper del personatge al Tirant lo Blanc," L'Espill 16 (1982): 27-44); Edward T. Aylward, Martorell's "Tirant lo Blanch": A Program for Military and Social Reform in Fiftcenth-Century Christendom, University of North Carolina Studies in Romance Languages and Literatures, Chapel Hill: University of North Carolina Press, 1985; Harriet Goldberg, "Clothing in Tirant lo Blanc: Evidence of "realismo vitalista" or of a New Unreality," Hispanic Review 52 (1984): 379-92; y Curt Wittlin, "Especulacions psicoanalitiques sobre la sexualitat en el Tirant lo Blanc," Llengua \& Literatura I (1986): 31-49.

${ }^{4}$ Libre del valerós e strenu cavaller Tirant lo Blanch, ed. de Marian Aguiló i Fuster. 4 vols., Barcelona: Biblioteca Catalana, 18731905.

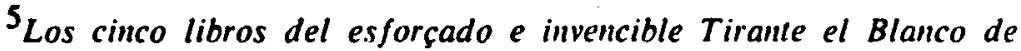
Roca Salada, cavallero de la Garrotera, Valladolid, 1511. Sólo queda un ejemplar de la edición, al que faltan dos folios, y que guarda la Biblioteca de Cataluña. Está editada, con el título de Tirante el Blanco, y con introducción y notas del mismo Riquer, en la col. de Clásicos Castellanos, 5 vols., Madrid: Espasa-Calpe, 1974. Hay otra traducción, moderna, de J. F. Vidal Jové, Madrid: Alianza Editorial, 1969. Recientemente ha sido traducida también al inglés por David Rosenthal (London: MacMillan, 1984), y al italiano, Tirante il Bianco (Roma: La Tipográfica, 1984). 


\section{CELESTINESCA}

${ }^{6}$ Federico $\mathrm{F}^{0}$ Curto Herrero, Estructura de los libros españoles de caballerias en el siglo XVI, Serie Universitaria, XII, Madrid: Fundación Juan March, 1976.

${ }^{7}$ Menéndez Pelayo, Origenes de la novela, Madrid: N.B.A.E., 1925, t. I, págs. CCXL-CCXLIV.

${ }^{8}$ Para un estado de la cuestión sobre las relaciones entre el texto de Martorell y Don Quijote, véase Daniel Eisenberg. "Pero Pérez the Priest and his Comment on Tirant lo Blanch." Modern Language Notes 88 (1973): 321-330. Posteriormente al mismo, se pueden consultar Antonio Torres, El realismo del "Tirant lo Blanc" y su influencia en el "Quijote." Barcelona: Puvill, 1979; Josep M. Sola-Solé, "El Tirant i el Quixot," Miscel.lània Aramon i Serra, Barcelona: Curial, 1980, vol. I, págs. 543-52, y E. T. Aylward, Martorell, esp. págs. 198-200.

${ }^{9}$ Para un resumen del argumento de la obra, se puede acudir a la introd. de Riquer en la ed. citada, o bien al más sucinto de Justina Ruiz de Conde, El amor y el matrimonio secreto en los libros de caballerias, Madrid: Aguilar, 1948, págs. 107-119. Cada una de las citas irá siempre --salvo indicación--referida exclusivamente a uno de esos cuatro capítulos de la obra (págs. 370-85).

${ }^{10}$ Seguiremos la ed. de Dorothy S. Severin, La Celestina, Madrid: Alianza, 1969.

11 Martín de Riquer, "Fernando de Rojas y el primer acto de $L a$ Celestina," Revista de Filologia Española 41 (1957): 373-95.

12 Jean Paul Lecertua, "Le jardin de Mélibée," Trames: éludes Ibériques, Limoges, 1978, págs. 105-138. A propósito de su asociación entre el "secreto lugar" y lugar "oculto," o lugar del gozo (pág. 126), véase, infra, n. 17.

13 Lecertua, "Le jardin," 119-21: "l'image de porte se trouve parfois chargée de connotations sexuelles et associée au phantasme de la castration et de l'impuissance."

14 Mario Vargas Llosa, Lletra de batalla per "Tirant lo Blanc", Barcelona: Edicions 62, 1969, págs. 71-3.

15 Lecertua, "Le jardin," $121-2$.

16 Para el problema de los nombres, véanse lás últimas interpretaciones de Miguel. Garci-Gómez, "Eras e Crato mëdicos: Identificación e interpretación," Celestinesca 6,i (Mayo 1982): 9-14. y "Sobre el "plebérico corazón" de Calisto y la razón de Pleberio," Hispania 66 (1983): 202-8.

${ }^{17}$ Los ejemplos, a partir de las "artes poéticas" estudiadas por E. Faral, son muchos, pero quizás el más común a ambas tradiciones sea el 


\section{CELESTINESCA}

de la Historia destructionis Troiae de Guido de Columnis. Por algo remitia a èl el anónimo autor de Curial e Gïclfa, para ahorrarse la descripción de las que llamaba "les circumstànciés de la (...) bellesa de Laquesis," doncella de la protagonista: "mas aquell qui ho voldrà saber lija Guido de Columpnis allà on descriu la bellesa de Elena e sie content ab alló..." (ed. Ramon Aramon i Serra, Barcelona, p. 77). Guido de Columnis habia sido traducido al catalán por Jaume Conesa entre 1367 y 1375 (la obra está ed., Les Històries Troyanes de Guiu de Colupnes, ed. R. Miquel i Planas, Barcelona: Biblioteca Catalana, 1916). Pedro de Chinchilla tradujo--o mejor, versionó--la obra en 1443. La primera edición en castellano es de Burgos, 1490.

18 A propósito de "aquella proporción que ver yo no pude" en el auto VIl de la Celestina veremos una clara alusión a "lo vedado." Se trata, por supuesto, de una graciosa metáfora eufemistica de los órganos sexuales femeninos, siguiendo el precepto de, entre otras, la Poetria nova de Geoffroi de Vinsauf: "Taceo de partibus infra" (Edmund Faral, Les arts poétiques $d u X I I$ et $d u X I I I$ siecle, Paris: Champion, pág. 215). Lo notable es que la misma imagen se encuentre también en Tiranl y en uno de los episodios más procaces y divertidos de la obra: "E com [Tirant] v'u que se n'anava e ab.les mans no la podia tocar [a Carmusina]. allargà la cama. e posà-la-hi davall les faldes. e ab la sabata tocà-li en lo Iloc vedat, e la sua cama posà diits les seues cuixes" (cap. CLXXXIX). Otro eufemismo empleado por Martorell es "lo secret," en el cap. CCXXXI (cfi. Juan de Cardona, Tratado noble de amor, ed. Juan Fernández Jiménez, pág. 78: "De cierto la hermosura de fuera manifesıava hien la de las partes secretas," siguiendo literalmente la frase que utilizará, en la primera descripción de Lucrecia, el traductor de la Estoria muy verdadera de dos amantes, de Eneas Silvio).

${ }^{19}$ Para la fortuna del lopos, véase Peter N. Dunn, "'Materia la mujer. el hombre forma": Notes on the Development of a Lopean Topos," Homenaje a William L. Fichter, Madrid, 1971, págs. 189-99.

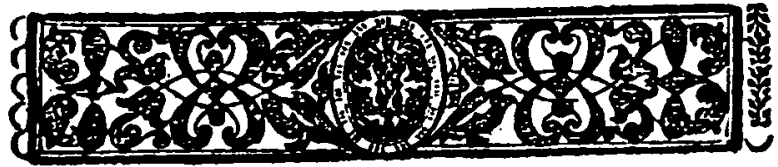




\section{CELESTINESCA}

\section{Ecleftina.}

\section{TR AGICOMEDIA DE CALISTO ET ME}

\section{LIBE A N VOV AMENTE.TRADOTTA}

Delingua Cafriglinna in Italiano idtame. A giomozi di mouo cutto quello che fin al giorno peefente li manas. wa. Dafoiogni oltra smpreffione nouj]jimamen te corrette, diftuma, ordinata, et in piu có mode forma iedotte, edomata les. qual afe nelle altre impreffione non ficrous.

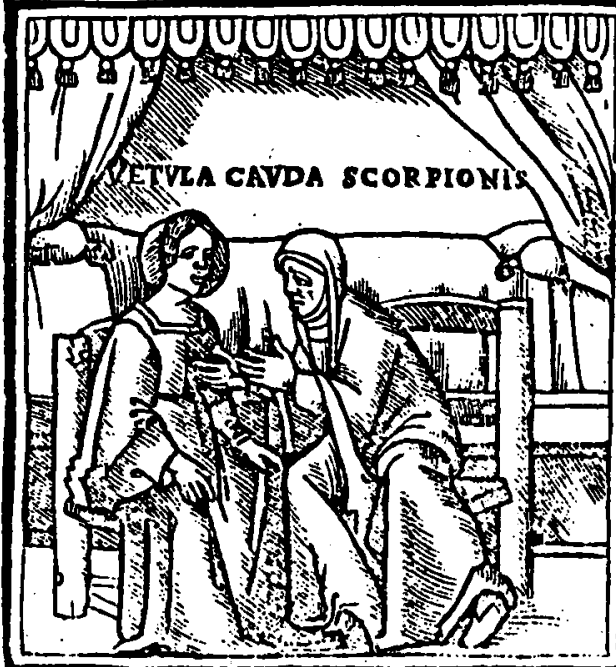

Titulo. Edición" "stampata per Pietro Nicolini da Sabio." Venecia 1535. 